\title{
Insulin Influences LPS-Induced TNF- $\alpha$ and IL-6 Release Through Distinct Pathways in Mouse Macrophages from Different Compartments
}

\author{
Fernando H. G. Tessaro ${ }^{a}$ Thais S. Ayala ${ }^{a}$ Eduardo L. Nolasco ${ }^{a}$ Leonardo M. Bella \\ Joilson O. Martins ${ }^{a}$ \\ aLaboratory of Immunoendocrinology, Department of Clinical and Toxicological Analyses, Faculty of \\ Pharmaceutical Sciences of University São Paulo (FCF/USP), São Paulo, Brazil
}

\section{Key Words}

Alloxan • Diabetes $\cdot$ Macrophage $\cdot \mathrm{PI} 3 \mathrm{~K} \cdot \mathrm{ERK} \cdot \mathrm{Akt}$

\begin{abstract}
Background/Aims: Diabetic subjects are more susceptible to infections, which is partially due to insulin deficiency and hyperglycemia. We hypothesized that insulin influences cytokine release by macrophages from diabetic C57BL/6 mice stimulated with lipopolysaccharides (LPS). Methods: Bone marrow-derived macrophages (BMDM) and tissue-specific macrophages from diabetic (alloxan $60 \mathrm{mg} / \mathrm{kg}$, i.v.) male C57BL/6 mice were stimulated by LPS (100 ng/mL) and/or treated by insulin (1 mU/mL). Results: Using BMDM from diabetic mice, we showed that LPS induced an increase in TNF- $\alpha$ and IL- 6 release and p38, SAPK/JNK, ERK 1/2, and Akt (308-Thr and 473-Ser) phosphorylation but not in PKC $\alpha / \beta$ II and delta. Insulin increased TNF- $\alpha$ and IL-6 secretion in LPS-stimulated macrophages as well as p-p38, p-SAPK/JNK, p-ERK 1/2, p-PI3K (p55) and p-Akt (473-Ser) expression. Furthermore, PI3-kinase inhibition by wortmannin decreased TNF- $\alpha$ release, and inhibition by LY294002 decreased both TNF- $\alpha$ and IL- 6 levels after LPS-insulin treatment. PD98059, which inhibits the ERK upstream activators MAPK kinase (MKK) 1 and MKK2, reduced the effect promoted by insulin in BMDM stimulated by LPS In tissue-specific macrophages, insulin reduced LPS-induced TNF- $\alpha$, IL- 6 and IL- $1 \beta$ secretion in alveolar and peritoneal macrophages. Conclusion: These data suggest that insulin through the modulation of PI3-kinase and ERK 1/2 pathways drive different responses in macrophages, thereby enhancing our understanding of the plasticity of these cells.
\end{abstract}

(C) 2017 The Author(s)

Published by S. Karger AG, Basel

\section{Introduction}

Insulin is a peptide hormone secreted by $\beta$ cells located in pancreatic islets [1]. $\beta$ cell destruction compromises insulin secretion, which deregulates glucose homeostasis and 


\section{Cellular Physiology Cell Physiol Biochem 2017;42:2093-2104 \begin{tabular}{ll|l} 
DOI: 10.1159/000479904 & Ond 2017 The Author(s). Published by S. Karger AG, Basel \\
www.karger.com/cpb
\end{tabular} \\ Tessaro et al.: Insulin Regulates Cytokine Production by Macrophages}

leads to a condition known as diabetes mellitus (DM) $[1,2]$. According to the American Diabetes Association (ADA), infections are a particular issue for diabetic patients due to immune system failure [2], and after insulin has been introduced to treat diabetic patients, the number of infections and complications related to these populations has decreased [1-3].

Macrophages are multifunctional cells that are found virtually in every tissue of the body and play a pivotal role in inflammatory response secreting inflammatory mediators [4]. Macrophages have compromised functions in diabetic individuals, which is partially responsible for their enhanced susceptibility to infections [5]. Moreover, by using different experimental models of diabetes, such as type I diabetes induced by alloxan or streptozotocin, and insulin resistance mice model, helps to explain the high susceptibility to infections in these subjects through a decrease in the capacity of insulin to interact with insulin-sensitive tissues (such as liver, fat and muscle). Consequently, it may lead to impairment of glucose utilization with consequently hepatic glucose output [6-11]. In addition, Gram-negative bacteria are responsible for approximately $25 \%$ of reported infections in the diabetic population [12]. These microorganisms feature in the cell walls a unique component known as lipopolysaccharide (LPS) [13]. LPS activates macrophages by interacting with Toll-like receptor (TLR)4 signaling via myeloid differentiation primary response gene 88 (MyD88)and TIR-domain-containing adapter-inducing interferon- $\beta$ (TRIF)-dependent pathways that culminate in pro-inflammatory events due to interactions among multiple signaling pathways $[13,14]$.

LPS stimulation leads to earlier mitogen-activated protein kinase (MAPK) activation by MyD88 [15]. MAPK are a group of molecules that regulate diverse cellular programs by relaying extracellular signals to intracellular responses $[15,16]$. The most studied MAPK are extracellular-signal-regulated kinase (ERK 1/2), stress-activated protein kinase/ Jun amino-terminal kinase (SAPK/JNK) and p38 [16]. ERK1/2 activation occurs through mitogen-activated protein kinase kinase (MEK)1 and MEK2 and involves the release of tumor progression locus 2 (Tpl2) from subunit 105, which is crucial for cytokine release [17]. SAPK/JNK and p38 activation by LPS promotes the synthesis and release of proinflammatory mediators by macrophages [18]. In addition, p38 activates mitogen-activated protein kinase-activated protein kinase 2 (MK2), which indirectly regulates Akt activity by controlling phosphatidylinositol 3, 4,5-trisphosphate $\left(\mathrm{PIP}_{3}\right)$ availability; therefore, the down-regulation of MK2 diminishes PIP $_{3}$ production and decreases Akt activity [19]. PI3K/ Akt signaling plays an important role in cell survival $[20,21]$. PI3K consists of a catalytic subunit (p110) and two regulatory subunits (p85 and p55) [20] and phosphorylates phosphatidylinositol 4, 5-bisphosphate $\left(\mathrm{PIP}_{2}\right.$ ) to generate $\mathrm{PIP}_{3}$. $\mathrm{PIP}_{3}$ is responsible for recruiting both phosphoinositide-dependent protein kinase 1 (PDK1) and Akt to the cell membrane, where PDK1 phosphorylates Akt [22]. Akt comprises a family of serine-threonine protein kinases that regulate cellular responses [23]. In an inflammatory process, PI3K/Akt signaling-controls macrophage response during the course of immune response [21, 23].

Insulin is primarily involved in metabolism regulation, and acts modulating immune cell responses via insulin receptors [24]. We hypothesize that insulin might play a role in regulating cytokine secretion by macrophages from diabetic mice. In this study, we performed an in vitro study to investigate the insulin effects in LPS-induced cytokine release by macrophages from different compartments. We found that insulin did not affect LPSstimulated tumoral necrosis factor (TNF)- $\alpha$ and interleukin (IL)- 6 released by bone marrowderived macrophages (BMDM) from non-diabetic mice, although this hormone increased the cytokine release by LPS-stimulated BMDM from diabetic mice. In addition, insulin increased LPS-induced p-p38, p-SAPK/JNK, p-ERK 1/2, p-PI3K (p55) and p-Akt (473-Ser) levels. In tissue-specific macrophages, insulin decreased LPS-induced TNF- $\alpha$, IL- 6 and IL- $1 \beta$ secretion by both alveolar and peritoneal macrophages. In our study, we demonstrated that insulin plays an important role in macrophages from diabetic mice by distinctly influencing the macrophages response from different tissues. 


\section{Cellular Physiology Cell Physiol Biochem 2017;42:2093-2104 \begin{tabular}{ll|l} 
and BiOChemistry & $\begin{array}{l}\text { DOI: 10.1159/000479904 } \\
\text { Published online: August 14, } 2017\end{array}$ & $\begin{array}{l}\text { (c) } 2017 \text { The Author(s). Published by S. Karger AG, Basel } \\
\text { www.karger.com/cpb }\end{array}$
\end{tabular}}

\section{Materials and Methods}

Animals and ethics statement

Forty-two specific pathogen-free male C57BL/6 mice (8-12 weeks old, wild-type phenotype, and weighing $25 \pm 2 \mathrm{~g}$ at baseline) were used. The animals were maintained at $23 \pm 2^{\circ} \mathrm{C}$ under a 12 -h light:dark cycle. Food and water were provided ad libitum before and during the experimental period. This study was conducted in strict accordance with the principles and guidelines of the National Council for the Control of Animal Experimentation (CONCEA) and approved by the Ethics Committee on Animal Use (CEUA) at the School of Pharmaceutical Sciences (FCF), University of São Paulo, Brazil (protocol number: CEUA/FCF/339). Cellular content was collected under ketamine/xylazine anesthesia, and all efforts were made to minimize animal suffering.

\section{Induction of diabetes mellitus}

Diabetes mellitus was induced via intravenous injection of $60 \mathrm{mg} / \mathrm{kg}$ of alloxan monohydrate (Sigma Chemical Co, St. Louis, Mo) dissolved in physiological saline $(0.9 \% \mathrm{NaCl})$, as previously described [25]. After 10 days, the glycemia of the animals was measured using Accu-Chek Advantage II (Roche Diagnostics, São Paulo, SP, Brazil). Only animals with glycaemia levels above $300 \mathrm{mg} / \mathrm{dL}$ were considered diabetic for this study.

\section{Cell isolation and cell culture}

Bone marrow-derived macrophages. BMDM were obtained as previously described [26]. Briefly, bone marrow was collected from femurs and cultured in RPMI-1640 (Gibco, Gaithersburg, MD, USA) medium supplemented with 20\% fetal bovine serum (FBS) (Sigma Chemical Co, St. Louis, Mo, USA), 30\% L929cell conditioned medium and gentamicin (Gibco, Gaithersburg, MD, USA) $\left(40 \mathrm{mg} / \mathrm{L}\right.$ ), at $37^{\circ} \mathrm{C}$ in a $5 \% \mathrm{CO}_{2}$ atmosphere. After four days, the cells received a fresh supplemented medium and were incubated for three additional days. Macrophages were collected from the dishes using cold phosphate buffered saline (PBS) and incubated in RPMI-1640 medium supplemented with 10\% FBS, 5\% L929-cell conditioned medium and gentamicin (Gibco, Gaithersburg, MD, USA) (' $40 \mathrm{mg} / \mathrm{L}$ ), at $37^{\circ} \mathrm{C}$ in a $5 \% \mathrm{CO}_{2}$ atmosphere. The next day, the cells were washed with warm PBS to remove non-adherent cells and FBS.

Tissue-specific macrophages: alveolar and peritoneal macrophages. Alveolar and peritoneal macrophages were obtained by lung lavage and peritoneal lavage, respectively, using sterilized cold PBS pH 7.4. The cells were allowed to adhere for $2 \mathrm{~h}\left(37^{\circ} \mathrm{C}, 5 \% \mathrm{CO}_{2}\right)$, followed by three washes with warm PBS. The cells were cultured overnight in RPMI- 1640 containing $10 \%$ FBS. The next day, the cells were washed with warm PBS to remove non-adherent cells and FBS.

\section{Cell treatments}

BMDM and tissue-specific macrophages were seeded and incubated in RPMI 1640 (Sigma Chemical Co, St. Louis, Mo, USA). The cells were treated at a final concentration of $1 \mathrm{mU} / \mathrm{mL}$ of insulin from bovine pancreas [27] (Sigma Chemical Co, St. Louis, Mo, USA) concomitantly stimulated with or without LPS (100 $\mathrm{ng} / \mathrm{mL}$ ) from Escherichia coli (serotype 055:B5) (Sigma Chemical Co, St. Louis, Mo, USA) for different time point in different assays. For the inhibition assay, BMDM from diabetic animals were pre-treated with inhibitors for PI3K (10 $\mu$ M LY294002 and/or $10 \mathrm{nM}$ wortmannin); ERK1/2 (2 $\mu$ M PD98059) and/or p38 (10 $\mu \mathrm{M}$ SB20190) for $1 \mathrm{~h}$ before LPS and/or insulin addition [28]. PI3K inhibitors were added together with LPS and/or insulin. All pharmacological inhibitors were purchased from Cell Signaling Technologies (Danvers, MA, USA).

\section{Cell viability assay}

The viability of BMDM from diabetic mice was evaluated after $24 \mathrm{~h}$ using propidium iodide (PI) staining. Macrophages were detached from the plate with $10 \mathrm{mM}$ PBS and EDTA solution. Cells were labeled with anti-mouse PI (Thermo Fisher Scientific Inc., Rockford, IL, USA) at a 1/100 dilution, acquired on a BD FACSCanto II flow cytometer (São Paulo, SP, Brazil) and analyzed using FlowJo Software 9.9.5 (Treestar, Ashland, OR, USA).

\section{KARGER}




\section{Cellular Physiology Cell Physiol Biochem 2017;42:2093-2104 \begin{tabular}{l|l|l} 
and Biochemistry Published online: August 14, 2017 & $\begin{array}{l}\text { (c) } 2017 \text { The Author(s). Published by S. Karger AG, Basel } \\
\text { www.karger.com/cpb }\end{array}$
\end{tabular}}

\section{Electrophoresis and immunoblotting}

Protein concentrations were determined using Pierce BCA Protein Assay Kit (Thermo Fisher Scientific Inc., Rockford, IL). Protein samples containing $20 \mu \mathrm{g}$ were separated using $10 \%$ sodium dodecyl sulfatepolyacrylamide gel electrophoresis and transferred to nitrocellulose membranes using the Amersham Te 70 Pwr Semi-Dry Transfer system (Amersham Biosciences Corp., Piscataway, NJ, USA). For immunoblotting, nitrocellulose membranes were incubated in Tris-buffered saline-Tween (TBS-T) buffer (150 mM NaCl, 20 mM Tris, 1\% Tween 20, pH 7.4) containing 5\% non-fat milk dried milk for 1 h. Afterwards, the membranes were washed with TBS-T buffer three times for $5 \mathrm{~min}$ each. Then, the membranes were incubated for 12$14 \mathrm{~h}$ with primary antibodies (1:1000 dilution) against phospho-ERK 1/2 MAP Kinase (Thr183/Tyr185), phospho-p38 MAP Kinase (Thr180/Tyr182), phospho-Akt (308-Thr), phospho-Akt (473-Ser), phospho-PI3 Kinase p85 (Tyr458)/p55 (Tyr199), Phospho-PKC $\alpha / \beta$ II (Thr638/641) and phospho-PKCdelta (Tyr311) diluted in $5 \%$ bovine serum albumin in TBS-T at $4^{\circ} \mathrm{C}$. The antibodies were purchased from Cell Signaling Technology (Beverly, MA, USA). Membranes were incubated with anti-rabbit secondary antibody (1:10000) for $1 \mathrm{~h}$ (Abcam), and developed using enhanced chemiluminescence detection over the nitrocellulose membrane. Band densities were determined by densitometric analysis using Image Studio Lite Version 5.2. The density values of the bands were normalized in each lane to that of $\beta$-actin or glyceraldehyde 3-phosphate dehydrogenase (GAPDH) (Sigma Chemical Co, St. Louis, Mo, USA).

Enzyme-linked immunosorbent assay

Cells were cultured at different time points, and supernatants were collected, centrifuged, and analyzed by enzyme-linked immunosorbent assay (ELISA) using cytokine-specific kits (R\&D Systems, Minneapolis, MN, USA).

\section{Statistical analysis}

The data are presented as the mean \pm SEM from at least three independent experiments. Statistical analyses were performed using GraphPad 6 software (San Diego, CA, USA), and Student's $t$-test and analysis of variance (ANOVA) followed by the Tukey-Kramer or Holm-Sidak test to perform comparisons. A p value lower than 0.05 was considered statistically significant.

\section{Results}

Type 1 diabetes experimental model

After 10 days of alloxan injection, the mice exhibited a significant reduction in body weight (before alloxan injection: $26.11 \pm 0.38 \mathrm{~g} ; 10$ days thereafter: $23.82 \pm 0.29 \mathrm{~g}, \mathrm{n}=17$; $\mathrm{P}$ $<0.001$ ) and elevated blood glucose levels (before alloxan injection: $156.8 \pm 2.4 \mathrm{mg} / \mathrm{dL} ; 10$ days thereafter: $591.4 \pm 3.90, \mathrm{n}=17$; $\mathrm{P}<0.001$ ).

\section{Insulin amplifies cytokine secretion by LPS-stimulated BMDM from diabetic mice}

To understand the insulin effect under LPS stimulation in macrophages from nondiabetic and diabetic mice, we measured in LPS-induced TNF- $\alpha$ and IL- 6 secretion by BMDM. Insulin did not alter cytokine release by LPS-stimulated BMDM from non-diabetic mice (data not shown). Then, we investigated TNF- $\alpha$ (Fig. 1A) and IL-6 (Fig. 1B) release in a kinetic study using BMDM from diabetic mice. Compared to LPS-stimulated cytokine production, insulin treatment boosted LPS-induced TNF- $\alpha$ release by BMDM after 3, 6 and 12 h; IL-6 concentrations increased after 6 and $12 \mathrm{~h}$ under these same conditions. However, insulin did not alter TNF- $\alpha$ and IL- 6 secretion after $24 \mathrm{~h}$ of LPS stimulation.

\section{Insulin does not affect the viability of BMDM from diabetic mice}

We assessed whether cell viability was altered by insulin (1 mU/mL) and/or LPS (100 $\mathrm{ng} / \mathrm{mL}$ ). We stained BMDM from diabetic mice with PI and measured cell viability after $24 \mathrm{~h}$ via flow cytometry (Fig. 1C). Incubation for $24 \mathrm{~h}$ did not affect BMDM viability. Thus, we next investigated protein phosphorylation after insulin treatment and LPS stimulus in BMDM from diabetic animals. 
Fig. 1. Insulin enhances LPS-induced TNF- $\alpha$ and IL-6 secretion in bone marrow-derived macrophages from diabetic mice without altering cell viability. Bone marrow-derived macrophages (BMDM) from diabetic mice were incubated with insulin (1 $\mathrm{mU} / \mathrm{mL}$ ) and simultaneously stimulated with LPS (100 ng/mL) in a kinetic study. (A) TNF- $\alpha$ and (B) IL-6 secretion by BMDM from diabetic mice was determined by ELISA. (C) BMDM viability from diabetic mice after $24 \mathrm{~h}$ was determined via flow cytometry after propidium iodide

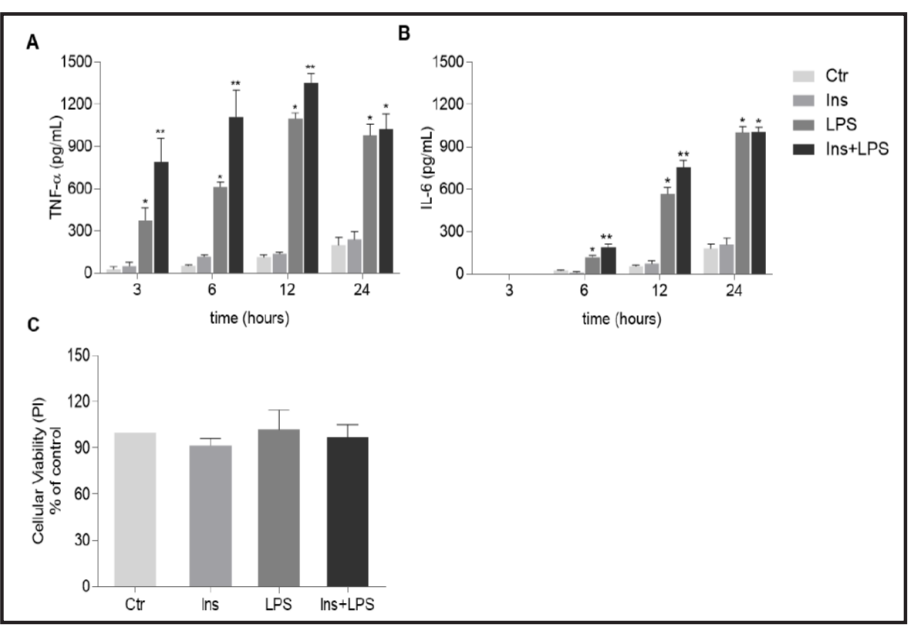
staining. The data represent the mean \pm SEM from five independent experiments. ${ }^{*} \mathrm{P}<0.05$ versus vehicle control; ${ }^{* *} \mathrm{P}<0.05$ versus LPS.

Fig. 2. Insulin enhances LPSinduced MAPK phosphorylation in bone marrow-derived macrophages from diabetic mice. Bone marrow-derived macrophages (BMDM) from diabetic mice were incubated with insulin $(1 \mathrm{mU} / \mathrm{mL})$ and simultaneously stimulated with LPS (100 ng/mL) for 60 min. (A) p38, ERK 1/2 (p42/ p44), SAPK/JNK (p46/p54) and GAPDH protein levels in BMDM from diabetic mice were determined by Western blotting. Relative (B) p38, (C) p42 MAPK, (D) p44 MAPK, (E) p46 SAPK/JNK and (F) p56 SAPK/JNK levels were determined by densitometry

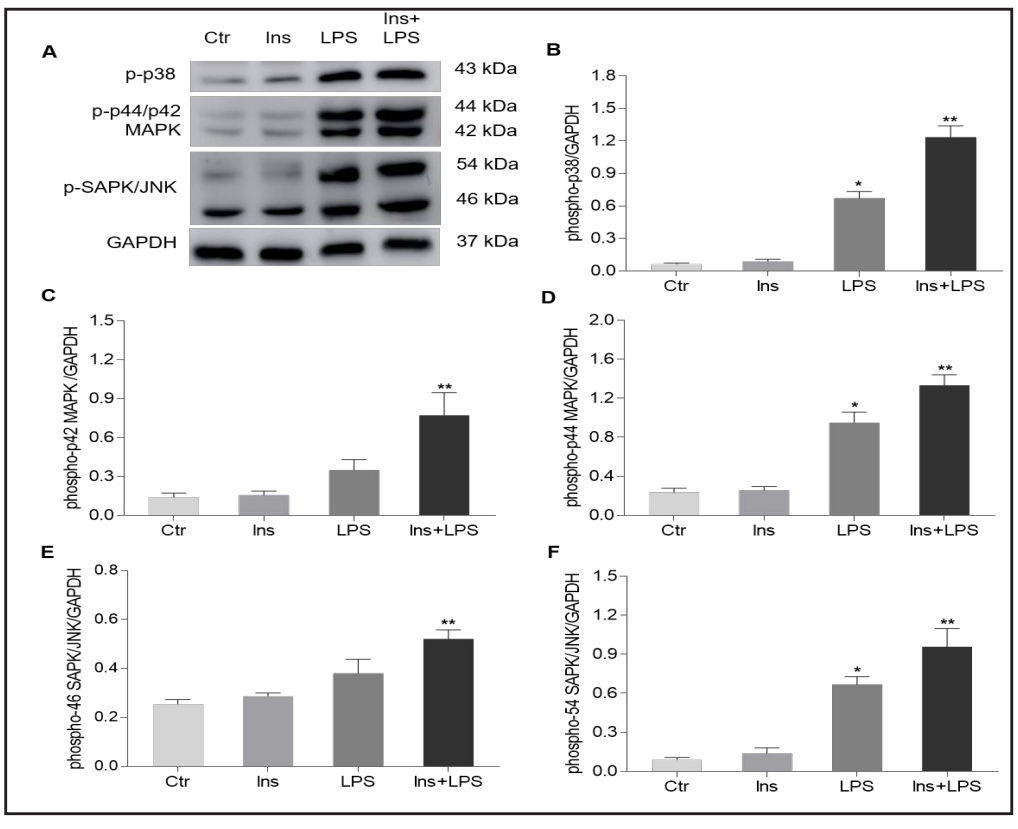
(GAPDH was used as a control). For all conditions, data represent the mean \pm SEM from five independent experiments. ${ }^{*} \mathrm{P}<0.05$ versus vehicle control; ${ }^{* *} \mathrm{P}<0.05$ versus $\mathrm{LPS}$.

Insulin enhances LPS-induced MAPK phosphorylation in BMDM from diabetic mice

To understand the effects of insulin on LPS-induced signaling pathways, we checked MAPK phosphorylated proteins in BMDM from diabetic mice using Western blotting (Fig. 2A). We analyzed p38 (Fig. 2B); p42 (Fig. 2C) and p44 ERK (Fig. 2D), also known as ERK 1/2, p46 (Fig. 2E) and p54 SAPK/JNK (Fig. 2F). We found that LPS induced MAPK activation but that insulin alone did not. Simultaneously, insulin treatment increased LPS-induced MAPK phosphorylation in diabetic BMDM, suggesting that MAPK may be involved in the enhancement of cytokine release by insulin.

\section{Effects of insulin on LPS-induced PI3K/Akt signaling}

The effect of insulin on LPS-induced PI3K/Akt phosphorylation in BMDM from diabetic mice was evaluated using Western blotting (Fig. 3A). As a control, neither LPS nor insulin 
Fig. 3. - Insulin enhances LPS-induced PI3K/ Akt phosphorylation in bone marrow-derived macrophages from diabetic mice. Bone marrow-derived macrophages (BMDM) from diabetic mice were incubated with insulin (1 $\mathrm{mU} / \mathrm{mL}$ ) and simultaneously stimulated with LPS (100 ng/mL) for 60 min. (A) PI3K p85 and p55, Akt (308-Thr), Akt (473-Ser), and $\beta$-actin protein levels in BMDM from diabetic mice were determined by Western blotting. Relative (B) PI3K p85, (C) PI3K p55, (D) Akt (308-Thr) and

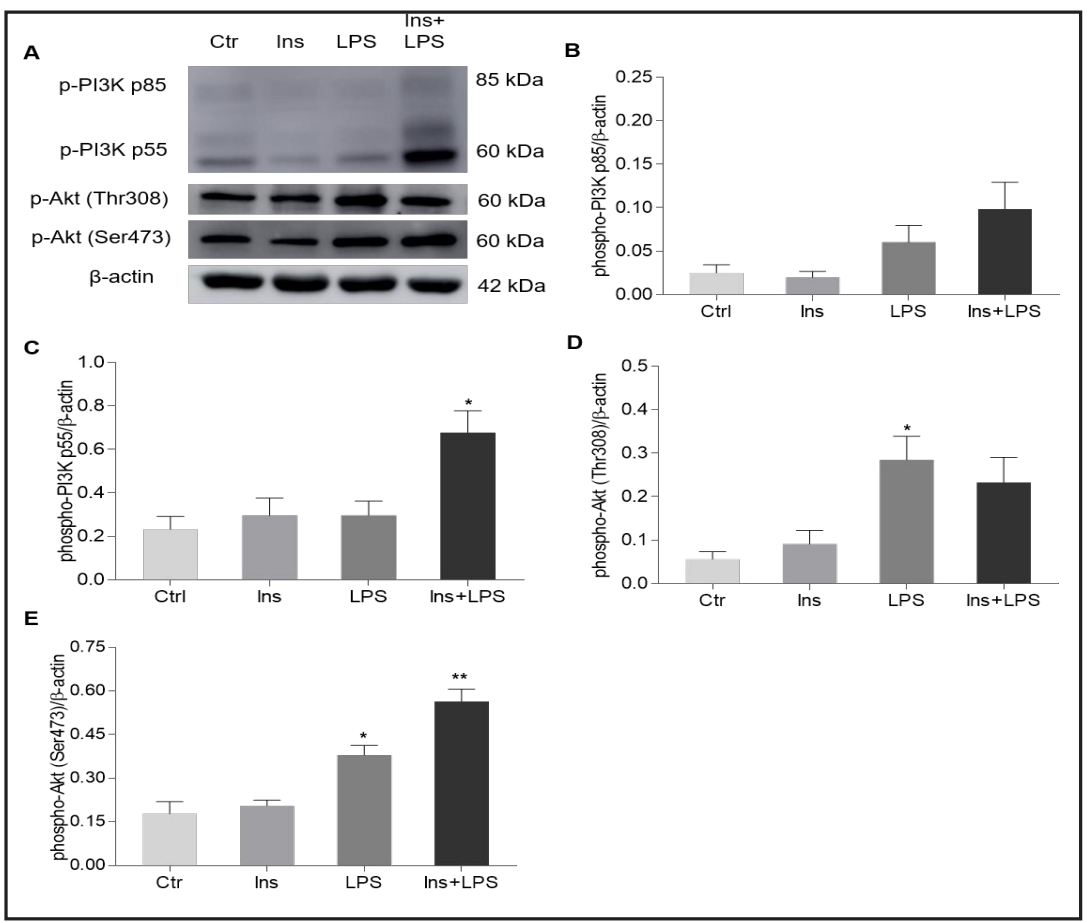
(E) Akt (473-Ser) levels were determined by densitometry ( $\beta$-actin was used a control). In all circumstances, the data represent the mean \pm SEM from five independent experiments. ${ }^{*} \mathrm{P}<0.05$ versus vehicle control; ${ }^{* *} \mathrm{P}<0.05$ versus LPS.

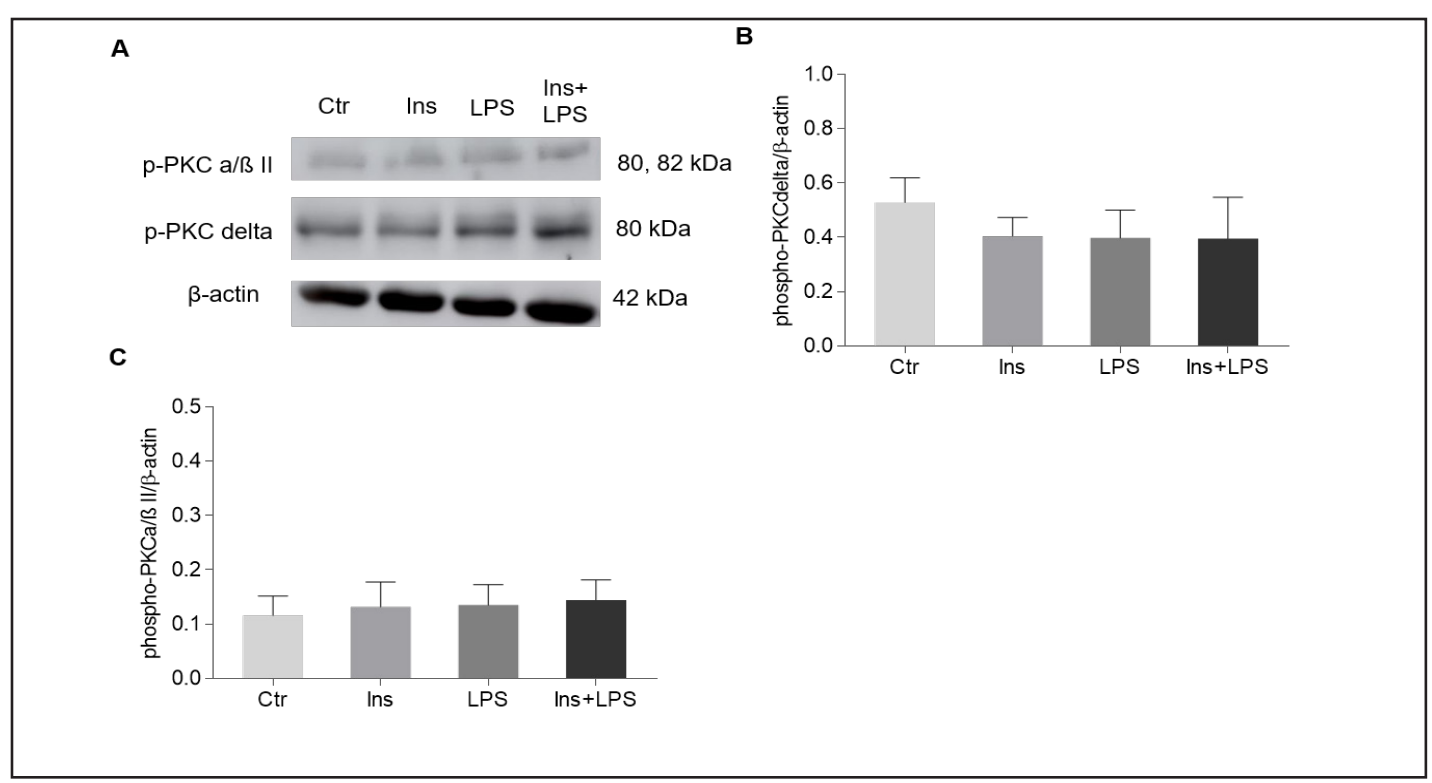

Fig. 4. Insulin and/or LPS do not alter PKC phosphorylation in bone marrow-derived macrophages from diabetic mice. Bone marrow-derived macrophages (BMDM) from diabetic mice were incubated with insulin $(1 \mathrm{mU} / \mathrm{mL})$ and simultaneously stimulated with LPS $(100 \mathrm{ng} / \mathrm{mL})$ for $60 \mathrm{~min}$. (A) PKC a/B, PKC delta and $\mathrm{b}$-actin protein levels in BMDM from diabetic mice were determined by Western blotting. Relative (B) PKC $\mathrm{a} / \mathrm{B}$ and (C) PKC delta levels were determined by densitometry (b-actin was used as a control). For all conditions, the data represent the mean \pm SEM from five independent experiments.

alone altered p85 (Fig. 3B) and p55 (Fig. 3C) phosphorylation. Insulin induced higher phosphorylation in the catalytic p55 domain, but not in p85 in LPS-stimulated macrophages. 


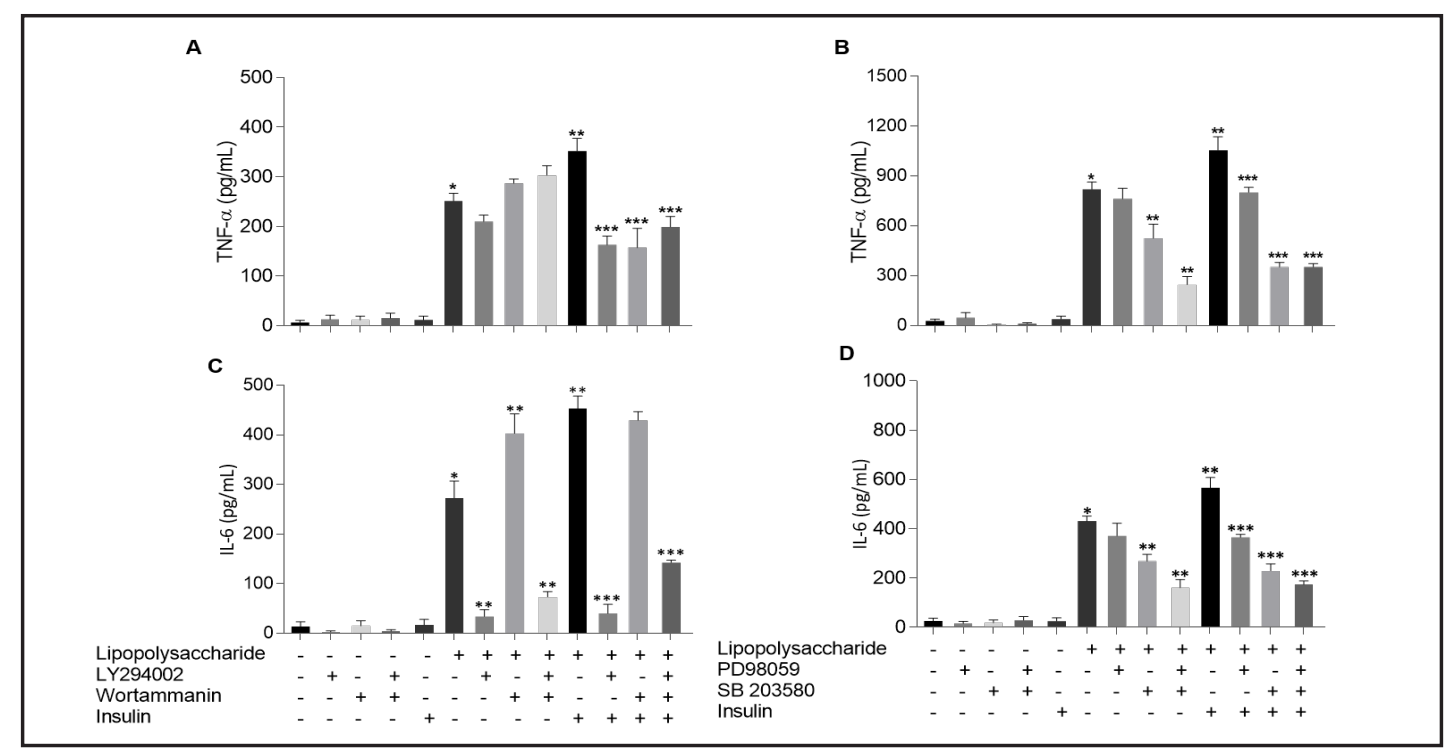

Fig. 5. Insulin enhances LPS-induced cytokine secretion in bone marrow-derived macrophages from diabetic mice via PI3K and ERK1/2. Bone marrow-derived macrophages (BMDM) were pre-treated with selective inhibitors of (A) (C) PI3K (10 nM wortmannin and $10 \mu \mathrm{M} \mathrm{LY294002)} \mathrm{and} \mathrm{(B)} \mathrm{(D)} \mathrm{ERK1/2} \mathrm{(2} \mu \mathrm{M}$ PD98059) or p38 (SB20190 $10 \mu \mathrm{M}$ ) and then incubated with insulin and/or LPS. BMDM from diabetic mice were incubated with insulin $(1 \mathrm{mU} / \mathrm{mL})$ and simultaneously stimulated with LPS (100 ng/mL) for $6 \mathrm{~h}$. (A) (B) TNF- $\alpha$ and (C) (D) IL-6 secretion by BMDM from diabetic mice was determined by ELISA. The data represent the mean \pm SEM from four independent experiments. ${ }^{*} \mathrm{P}<0.05$ versus vehicle control; ${ }^{*} \mathrm{P}<0.05$ versus LPS; ${ }^{* * *} \mathrm{P}<0.05$ versus Ins + LPS.

To further understand this phenomenon, we examined Akt phosphorylation at both 308Thr (Fig. 3D) and 473-Ser (Fig. 3E). LPS induced Akt phosphorylation at both 308-Thr and 473-Ser, whereas insulin alone did not alter Akt phosphorylation. Simultaneously, insulin treatment of LPS-stimulated BMDM increased Akt phosphorylation at 473-Ser.

\section{Effects of insulin on LPS-induced PKC activation}

To understand the effects of insulin treatment on LPS-induced PKC phosphorylation in BMDM from diabetic mice (Fig. 4A), we analyzed by Western blot the phosphorylation of PKC isoforms $\alpha / \beta$ II (Fig. 4B) and delta (Fig. 4C) and found out that insulin treatment did not activate PKC isoforms from diabetic mice with or without LPS stimulation.

Insulin enhances TNF- $\alpha$ and IL-6 secretion by LPS-stimulated BMDM via PI3K and ERK

We use pharmacological inhibitors to investigate the importance of PI3K phosphorylation in insulin-enhanced cytokine secretion. BMDM were treated with two specific PI3K inhibitors, wortmannin and LY294002. The effect of insulin on LPS-induced TNF- $\alpha$ (Fig. 5A) and IL-6 (Fig. 5C) by BMDM from diabetic mice was abolished by LY294002, whereas wortmannin abolished only TNF- $\alpha$ release. In addition, we investigated insulin amplification of LPS-induced TNF- $\alpha$ and IL- 6 release by using two well-established pharmacological inhibitors of MEK1/2 (PD98059) and p38 (SB20190), which are responsible for inactivating ERK1/2 and p38, respectively. Pharmacological ERK inhibition had no effect on LPS-induced cytokine release, whereas p38 inhibition reduced LPS-induced TNF- $\alpha$ (Fig. 5B) and IL-6 (Fig. 5D) release. The effects of insulin on LPS-dependent TNF- $\alpha$ and IL-6 release by BMDM from diabetic mice were abolished by PD98056 (ERK 1/2 inhibition), while SB20190 (p38 inhibition) reduced the effect of insulin on LPS-induced TNF- $\alpha$ and IL- 6 release. Taken together, these data indicate that insulin enhances TNF- $\alpha$ and IL- 6 concentrations in BMDM stimulated with LPS via the PI3K and ERK pathways. 


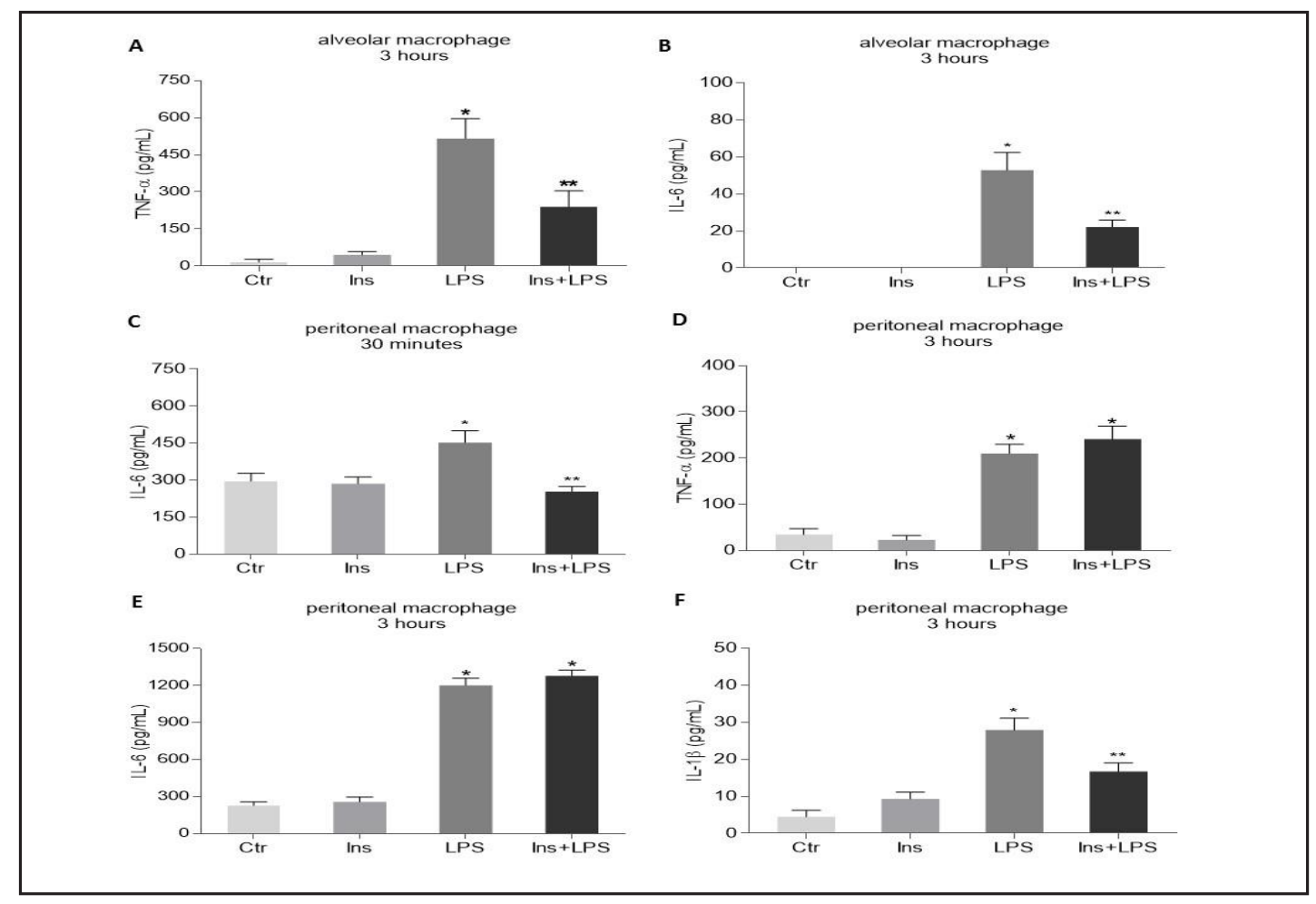

Fig. 6. Insulin inhibits LPS-induced pro-inflammatory cytokine secretion in alveolar and peritoneal macrophages from diabetic mice. Alveolar and peritoneal macrophages from diabetic mice were incubated with insulin (1 mU/mL) and simultaneously stimulated with LPS (100 ng/mL) for $30 \mathrm{~min}$ and $3 \mathrm{~h}$. (A) IL-6 and (B) TNF- $\alpha$ secretion by alveolar macrophages at $3 \mathrm{~h}$ min. (C) IL-6 secretion by peritoneal macrophages at 30 min. (D) TNF- $\alpha$, (E) IL-6 and (F) IL-1 $\beta$ secretion by peritoneal macrophages at $3 \mathrm{~h}$. Cytokine levels were determined by ELISA. The data represent the mean \pm SEM from five independent experiments. ${ }^{*} \mathrm{P}<0.05$ versus vehicle control; ${ }^{* *} \mathrm{P}<0.05$ versus LPS.

Insulin reduces LPS-induced pro-inflammatory cytokine secretion by alveolar and peritoneal macrophages from diabetic mice

We also investigated the effect of insulin on LPS-induced pro-inflammatory cytokine release in tissue-specific macrophage, alveolar and peritoneal macrophages. In alveolar macrophages (AM), LPS induced higher levels of TNF- $\alpha$ (Fig. 6A) and IL-6 (Fig. 6B) release compared to the control. Insulin reduced TNF- $\alpha$ and IL-6 secretion in AMs stimulated with LPS after 3 h. Peritoneal macrophages (PM) stimulated with LPS released higher levels of TNF- $\alpha$ (Fig. 6C), IL-1 $\beta$ (Fig. 6D) and IL-6 (Fig. 6E-6F) compared to controls. In addition, insulin decreased the LPS-induced release of IL- 6 after $30 \mathrm{~min}$ and IL-1 $\beta$ after $3 \mathrm{~h}$. Insulin alone did not affect TNF- $\alpha$ and IL- 6 concentrations after $3 \mathrm{~h}$, suggesting that insulin distinctly modulates the LPS response of resident macrophages from different tissues in diabetic mice.

\section{Discussion}

Accordingly with our findings, insulin positively regulated TNF- $\alpha$ and IL- 6 secretion by up-regulating p-p38, p-SAPK/JNK, p-ERK 1/2, p-PI3K (p55) and p-Akt (473-Ser). Furthermore, PI3-kinase inhibition by wortmannin decreased TNF- $\alpha$ release, and inhibition by LY294002 decreased both TNF- $\alpha$ and IL-6 after LPS-insulin treatment. PD98059, which inhibits MKK1 and MKK2, reduced the insulin effect on LPS-induced cytokine release in BMDM. In tissue-specific macrophages, insulin reduced LPS-induced TNF- $\alpha$, IL- 6 by AM and IL6 and IL-1 $\beta$ secretion by PM. 


\section{Cellular Physiology Cell Physiol Biochem 2017;42:2093-2104 \\ and Biochemistry Published online: August 14, 2017 \begin{tabular}{l|l} 
DOI: 10.1159/000479904 2017 The Author(s). Published by S. Karger AG, Basel \\
www.karger.com/cpb
\end{tabular} \\ Tessaro et al.: Insulin Regulates Cytokine Production by Macrophages}

Macrophages play a key role to regulate and avoid a prolonged inflammatory response exerting strict control against pathogens [4]. Cytokine release is an important process in homeostasis [4], and dysregulation in this mechanism in diabetic patients can be associated with high rates of infection [5]. After an extended period, the effects of diabetes itself including hyperglycemia and insulin deficiency can disrupt macrophage function $[2,29]$. Our results demonstrated that insulin increased LPS-induced cytokine secretion by BMDM, but decreased cytokine release in AM and PM, suggesting a modulatory effect promoted by insulin. In addition, insulin promoted distinctly effects in macrophages from different compartments and it can be due to macrophage actions according to the tissue microenvironment. It has recently been discussed extensively by Davies and Taylor [30], and by Perdiguero and Geissmann [31]. By acting on non-diabetic [27] and diabetic mononuclear cells [24], it has been demonstrated that insulin plays additional roles beyond glucose uptake [32] and seems to have important immunomodulatory effects in macrophages. Moreover, insulin binds to its own receptor and has different roles depending on the cell type. In 3T3L1 adipocytes, insulin increases p38 phosphorylation [33], whereas the opposite occurs in neuronal cells [34]. In addition, different concentrations of insulin activate p38 and ERK 1/2 without activating SAPK/JNK in vascular smooth muscle cells [35]. However, insulin-treated AM display no MAPK and Akt phosphorylation, and therefore do not exhibit alterations in TNF- $\alpha$ secretion [27]. In the present study, we showed that insulin alone had no effect on macrophages from diabetic mice.

Cytokines, such as TNF- $\alpha$ is enhanced in the presence of LPS and has influences on BMDM viability [36]. We found that LPS stimulation with or without insulin did not affect the viability of BMDM from diabetic mice, despite the change in the concentration of TNF- $\alpha$. In addition, macrophages from different compartments have different surveillance profiles. PI3K/Akt signaling and ERK 1/2 phosphorylation play a protective, anti-apoptotic role in osteoclasts, which is diminished when PI3K and ERK $1 / 2$ are inhibited, thus demonstrating the importance of both molecules in signal transduction [37]. Moreover, the role of p38 appears to be ambiguous, as p38 seems to activate Akt indirectly; their activation culminates in either death or survival depending on the cell type [37, 38]. ERK 1/2, p38, and SAPK/ JNK activation by LPS promotes synthesis and release of pro-inflammatory mediators by M1 macrophages during the inflammatory response $[16,18]$. In the present study, insulin treatment promoted higher cytokine release by LPS-stimulated BMDM from diabetic mice but not in LPS-stimulated BMDM from non-diabetic mice. Insulin appears to work together with LPS in PI3K p55 catalytic subunit phosphorylation to generate more $\mathrm{PIP}_{3}$ from $\mathrm{PIP}_{2}$. Insulin also selectively enhanced Akt phosphorylation at 473-Ser but not at 308-Thr. Somehow, the PI3K/Akt pathway appears connected with MAPK due to the higher levels of p38, ERK 1/2 and SAPK/JNK phosphorylation. As such, we suggest the existence of a bridge that connects LPS stimulation and insulin treatment that boosts the release of pro-inflammatory mediators by BMDM from diabetic mice. Furthermore, our macrophage studies using pharmacological inhibitors of PI3K, ERK $1 / 2$ and p38 helped us identify the proteins involved in the effect of insulin on LPS stimulation. We found that PI3K and ERK 1/2 inhibition significantly reduced the ability of insulin to boost LPS-induced cytokine release by BMDM from diabetic mice. Consistent with our results, insulin treatment in vitro in LPS- and interferon (IFN)- $\gamma$ stimulated non-diabetic PM promoted higher levels of IL-6 and TNF- $\alpha$ secretion, which was blocked by ERK inhibition [29].

In non-diabetic AM, insulin inhibits LPS-induced p38 and ERK 1/2 MAPK, PKC and Akt phosphorylation, resulting in reduced TNF- $\alpha$ levels [27]. Nevertheless, high concentrations of insulin promote ERK 1/2 but not Akt phosphorylation in PM; these high concentrations do not alter cytokine release [29]. However, according to our results in tissue-specific macrophages from diabetic mice, insulin promoted a reduction in LPS-induced TNF- $\alpha$ and IL- 6 released by AM, while IL 1- $\beta$ and IL- 6 secreted levels by PM. Under high glucose concentration, primary microglia showed increased sensitivity in vitro to LPS stimulus due to higher TLR4 expression and inflammatory cytokines secretion [34]. Moreover, in mononuclear cells from of type 1 diabetes patients, insulin infusion suppresses while glucose 


\section{Cellular Physiology Cell Physiol Biochem 2017;42:2093-2104 \begin{tabular}{ll|l} 
DOI: 10.1159/000479904 & O 2017 The Author(s). Published by S. Karger AG, Basel \\
www.karger.com/cpb
\end{tabular} \\ Tessaro et al.: Insulin Regulates Cytokine Production by Macrophages}

infusion induces TLR4 expression [39], which make stronger the concept that both insulin and glucose might modulate the macrophage functions.

\section{Conclusion}

Taken together, these data indicate that insulin drives different responses through distinct pathways in macrophages, thereby enhancing our understanding of the plasticity of these cells.

\section{Abbreviations}

ADA (American Diabetes Association); AM (Alveolar Macrophage); BMDM (Bone marrow-derived macrophage); CEUA (Ethics Committee on Animal Use); CONCEA (National Council for the Control of Animal Experimentation); DM (Diabetes mellitus); ELISA (Enzyme-linked immunosorbent assay); ERK 1/2 (Extracellular-signal-regulated kinases); FBS (Fetal Bovine Serum); FCF (School of Pharmaceutical Sciences);GAPDH (Glyceraldehyde 3-phosphate dehydrogenase); IL(Interleukin); IFN (Interferon); LPS (Lipopolysaccharide); MAPK (Mitogen-activated protein kinase); MEK (Mitogen-activated protein kinase kinase); MK2 (Mitogen-activated protein kinase-activated protein kinase 2); MyD88 (Myeloid differentiation primary response gene 88); PBS (Phosphate Buffered Saline); PDK1 (Phosphoinositide-dependent protein kinase 1); PI (Propidium Iodide); PI3K (Phosphoinositide 3-kinase); $\mathrm{PIP}_{2}$ (Phosphatidylinositol 4,5-biphosphate); $\mathrm{PIP}_{3}$ (Phosphatidylinositol 3,4,5-triphosphate); PKC (Protein Kinase C); PM (Peritoneal Macrophage); SAPK/JNK (Stress-activated protein kinases/Jun amino-terminal kinases); TLR (Toll-like receptor); TNF (Tumoral necrosis factor); Tpl2 (Tumor Progression Locus 2); TRIF (TIR-domain-containing adapter-inducing interferon- $\beta$ ); TSB-T (Tris-buffered SalineTween).

\section{Acknowledgements}

The authors would like to sincerely thank Mariana C.F. Silva for their expert technical help. The authors are supported by grant 2010/02272-0, 2012/23998-4 and 2014/052141 and 2017/15625-7 from São Paulo Research Foundation (FAPESP), grant 470523/20131 and 301617/2016-3 from National Counsel of Technological and Scientific Development (CNPq; Projeto Universal 2013 and PQ-1D), Coordenação de Aperfeiçoamento de Pessoal de Nível Superior (CAPES), and Pró-reitoria de Pesquisa da Universidade de São Paulo (PRP/ USP, Projeto I and Novos Docentes), Brazil.

\section{Disclosure Statement}

The authors declare that there is no conflict of interest that would prejudice the impartiality of this scientific work.

\section{References}

1 Atkinon MA, Eisenbarth GS, Michels AW: Type 1 diabetes. Lancet 2014;383:69-82.

2 American Diabetes Association: Strategies for improving care. Sec. 1. In Standards of Medical Care in Diabetes. Diabetes Care 2016;39:S6-S12.

3 International Diabetes Federation: IDF Diabetes Atlas. International Diabetes Federation 2015;7th edn. 


\section{Cellular Physiology Cell Physiol Biochem 2017;42:2093-2104

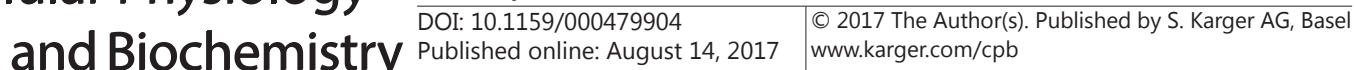

-4 Murray PJ, Wynn TA: Protective and pathogenic functions of macrophage subsets. Nat Rev Immunol 2011;11:723-737.

5 Casqueiro J, Casqueiro J, Alves C: Infections in patients with diabetes mellitus: A review pathogenesis. Indian J Endocrinol Metab 2012;16:27-36.

-6 Li J, Wei X, Xie Q, Hoa Pham TT, Wei J, He P, Jiao Y, Xu X, Giang Nguyen TH, Wen Q, Huang R: Protective Effects of 2-Dodecyl-6-Methoxycyclohexa-2, 5-Diene-1, 4-Dione Isolated from Averrhoa Carambola L. (Oxalidaceae) Roots on High-Fat Diet-Induced Obesity and Insulin Resistance in Mice. Cell Physiol Biochem 2016;40:993-1004.

-7 Xie Q, Zhang S, Chen C, Li J, Wei X, Xu X, Xuan F, Chen N, Pham T, Qin N, He J, Ye F, Huang W, Huang R, Wen Q: Protective Effect of 2-Dodecyl-6-Methoxycyclohexa-2, 5-Diene-1, 4-Dione, Isolated from Averrhoa Carambola L., Against Palmitic Acid-Induced Inflammation and Apoptosis in Min6 Cells by Inhibiting the TLR4-MyD88-NF-кB Signaling Pathway. Cell Physiol Biochem 2016;39:1705-1715.

8 Sindhu S, Al-Roub A, Koshy M, Thomas R, Ahmad R: Palmitate-Induced MMP-9 Expression in the Human Monocytic Cells is Mediated through the TLR4-MyD88 Dependent Mechanism. Cell Physiol Biochem 2016;39:889-900.

-9 Hozzein WN, Badr G, Al Ghamdi AA, Sayed A, Al-Waili NS, Garraud O: Topical application of propolis enhances cutaneous wound healing by promoting TGF-beta/Smad-mediated collagen production in a streptozotocin-induced type I diabetic mouse model. Cell Physiol Biochem 2015;37:940-954.

10 Xu X, Liang T, Lin X, Wen Q Liang X, Li W, Qin F, Zheng N, Ming J, Huang R: Effect of the Total Extract of Averrhoacarambola (Oxalidaceae) Root on the Expression Levels of TLR4 and NF- $\mathrm{BB}$ in StreptozotocinInduced Diabetic Mice. Cell Physiol Biochem 2015;36:2307-2316.

11 Sartorius T, Drescher A, Panse M, Lastovicka P, Peter A, Weigert C, Kostenis E, Ullrich S, Häring HU: Mice Lacking Free Fatty Acid Receptor 1 (GPR40/FFAR1) are Protected Against Conjugated Linoleic AcidInduced Fatty Liver but Develop Inflammation and Insulin Resistance in the Brain. Cell Physiol Biochem 2015;35:2272-2284.

12 Esper MA, Moss M, Martin GS: The effect of diabetes mellitus on organ dysfunction with sepsis: an epidemiological study. Crit Care 2008;13:R18.

13 Beutler B, Rietschel ET: Innate immune sensing and its roots: the story of endotoxin. Nat Rev Immunol 2003;3:169-176.

14 Lu YC, Yeh WC, Ohashin PS: LPS/TLR4 signal transduction pathway. Cytokine 2008;42:145-151.

15 Peroval MY, Boyd AC, Young JR, Smith AL: A Critical Role for MAPK Signalling Pathways in the Transcriptional Regulation of Toll Like Receptors. Plos One 2013;8:e51243.

16 Cargnello M, Roux PP: Activation and function of the MAPK and their substrates, the MAPK-activated protein kinases. Microbiol Mol Biol Rev 2011;75:50-83.

17 Dumitru CD, Ceci JD, Tsatsanis C, Kontoviannis D, Stamatakis K, Lin JH, Patriotis C, Jenkings NA, Copeland NG, Kollias G, Tsichlis PN: TNF- $\alpha$ Induction by LPS Is Regulated Posttranscriptionally via a Tpl2/ERKDependent Pathway. Cell 2000;103:1071-1083.

18 Sica A, Mantovani A: Macrophage plasticity and polarization: in vivo veritas. J Clin Invest 2012;122:787795.

19 McGuire VA, Gray A, Monk CE, Santos SG, Lee K, Aubareda A, Crowe J, Ronkina N, Schwermann J, Batty IH, Leslie NR, Dean JL, O’Keefe SJ, Boothby M, Gaestel M, Arthur JS: Cross talk between the Akt and p38 $\alpha$ pathways in macrophages downstream of Toll-like receptor signaling. Mol Cell Biol 2013;33:4152-4165.

20 Hemmings BA, Restuccia DF: PI3K-PKB/Akt Pathway. Cold Spring Harb Perspect Biol 2012;4:a011189.

21 Hawkins PT, Stephens LR: PI3K signalling in inflammation. Biochim Biophys Acta 2015;1851:882-897.

22 Hazeki K, Nigorikawa K, Hazeki O: Role of phosphoinositide 3-kinase in innate immunity. Biol Pharm Bull 2007;30:1617-1623.

23 Zhang Y, Wang X, Yang H, Liu H, Lu Y, Han L, Liu G: Kinase AKT controls innate immune cell development and function. Immunology 2013;140:143-152.

24 Dandona P, Ghanim H, Green K, Sia CL, Abuaysheh S, Kuhadiya N, Batra M, Drindsa S, Chaudhuri A: Insulin infusion suppresses while glucose infusion induces Toll-like receptors and high-mobility group-B1 protein expression in mononuclear cells of type 1 diabetes patients. Am J Physiol Endocrinol Metab 2013;304:810818. 


\section{Cellular Physiology Cell Physiol Biochem 2017;42:2093-2104

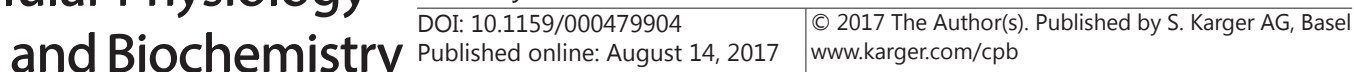

25 Spiller F, Carlos D, Souto FO, de Freitas A, Soares FS, Vieira SM, Paula FJ, Alves-Filho JC, Cunha FQ: $\alpha 1$-Acid Glycoprotein decreases neutrophil migration a dincreases susceptibility to sepsis in diabetic mice. Diabetes 2012;61:1584-1591.

-26 Yoshikawa FSA, Ferreira LG, de Almeida, SR: IL-1 signaling inhibits Trichophyton rubrum conidia development and modulates the IL-17 response in vivo. Virulence 2015;6:449-457.

27 Martins JO, Ferracini M, Ravanelli N, Landgraf RG, Jancar S: Insulin inhibits LPS-induced signaling pathways in alveolar macrophages. Cell Physiol Biochem 2008;21:297-304.

-28 Morato-Marques M, Campos MR, Kane S, Rangel AP, Lewis C, Ballinger MN, Kim SH, Peters-Golden M, Jancar S, Serezani CH: Leukotrienes Target F-actin/Cofilin-1 to Enhance Alveolar Macrophage Anti-fungal Activity. J Biol Chem 2011; 286:28902-28913.

29 Sun C, Sun L, Ma H, Peng J, Zhen Y, Duan K, Liu G, Ding W, Zhao Y: The phenotype and functional alterations of macrophages in mice with hyperglycemia for long term. J Cell Physiol 2012;227:1670-1679.

-30 Davies LC, Taylor PR: Tissue-resident macrophages: then and now: Tissue-resident macrophages: then and now. Immunology 2015; 144:541-548.

31 Perdiguero EG, Geissmann F: The development and maintenance of resident macrophages. Nat Immunol 2016;17:2-8.

-32 Freemerman AJ, Johnson AR, Sacks GN, Milner JJ, Kirk EL, Troester MA, Macintyre AN, Goraksha-Hicks P, Rathmell JC, Makowski L: Metabolic reprogramming of macrophages: glucose transporter 1 (GLUT1)mediated glucose metabolism drives a proinflammatory phenotype. J Biol Chem 2014;289:7884-7896.

33 Sweeney G, Somwar R, Ramlal T, Volchuk A, Ueyama A, Klip A: An inhibitor of p38 mitogen-activated protein kinase prevents insulin-stimulated glucose transport but not glucose transporter translocation in 3T3-L1 adipocytes and L6 myotubes. J Biol Chem 1999;274:10071-10078.

-34 Heidenreich KA, Kummer JL: Inhibition of p38 mitogen-activated protein kinase by insulin in cultured fetal neurons. J Biol Chem 1996;271:9891-9894.

-35 Igarashi M, Yamaguchi H, Hirata A, Daimon M, Tominaga M, Kato T: Insulin activates p38 mitogen-activated protein (MAP) kinase via a MAP kinase kinase (MKK) 3/MKK 6 pathway in vascular smooth muscle cells. Eur J Clin Invest 2000;30:668-677.

36 Lombardo E, Alvarez-Barrientos A, Maroto B, Bosca l, Knaus UG: TLR4-mediated survival of macrophages is MyD88 dependent and requires TNF-alpha autocrine signalling. J Immunol 2007;178:3731-3739.

-37 Lee ZH, Lee SE, Kim CW, Lee SH, Kim SW, Kwack K, Walsh K, Kim HH: IL-1alpha stimulation of osteoclast survival through the PI3-kinase/Akt and ERK pathways. J Biochem 2002;131:161-166.

-38 Seimon TA, Wang Y, Han S, Senokuchi T, Schrijvers DM, Kuriakose G, Tall AR, Tabas IA: Macrophage deficiency of p38alpha MAPK promotes apoptosis and plaque necrosis in advanced atherosclerotic lesions in mice. J Clin Invest 2009;119:886-898.

-39 Zhang X, Dong H, Zhang S, Jie L, Qian Y: Enhancement of LPS-Induced Microglial Inflammation Response via TLR4 Under High Glucose Conditions. Cell Physiol Biochem 2015;35:1571-1581. 